\title{
PARÂMETROS HEMATOLÓGICOS DA TILÁPIA-DO-NILO: EFEITO DA DIETA SUPLEMENTADA COM LEVEDURA E ZINCO E DO ESTÍMULO PELO FRIO
}

\author{
Altevir Signor, ${ }^{1}$ Luiz Edivaldo Pezzato, ${ }^{2}$ Dario Rocha Falcon, ${ }^{3}$ \\ Igo Gomes Guimarães ${ }^{4}$ e Margarida Maria Barros ${ }^{5}$ \\ 1. Docente da Universidade Estadual do Oeste do Paraná - Unioeste. \\ E-mail: altevirsignor@yahoo.com.br \\ 2. Professor doutor da FMVZ, Unesp \\ 3. Professor adjunto da Universidade Federal Rural de Pernambuco \\ 4. Professor adjunto nível 1 da Universidade Federal de Goiás \\ 5. Professora doutora da FMVZ, Unesp.
}

\section{RESUMO}

Objetivou-se avaliar os parâmetros hematológicos da tilápiado-nilo alimentada com dietas suplementadas com níveis de levedura autolisada e zinco, anterior e posterior ao estímulo pelo frio. As dietas foram formuladas para conter $32,0 \% \mathrm{PD}$ e $3.240 \mathrm{kcal} \mathrm{ED} / \mathrm{kg}$ com adição de levedura autolisada (\%) e zinco (mg/kg): 0,0:0,0; 0,0:79,5; 2,0:0,0; 0,795:79,5;2,0:200; 4,0:400; 6,0:600; 12,0:1200 e 14,0:1400. $\mathrm{Na}$ fase I, 135 alevinos foram distribuídos em 27 aquários de 50L e alimentados quatro vezes/dia por 128 dias $\left(26^{\circ} \mathrm{C}\right)$. Posteriormente, iniciou-se a fase II. Nove peixes/tratamento foram transferidos para 27 aquários de $40 \mathrm{~L}$ (três/aquário) e submetidos à baixa temperatura $\left(13,0^{\circ} \mathrm{C}\right)$ por sete dias. Antes e após o estímulo pelo frio avaliaram- se: o número de eritrócitos, a porcentagem de hematócrito, a taxa de hemoglobina, o volume corpuscular médio, a concentração de hemoglobina corpuscular média, a proteína plasmática e leucócitos totais, a porcentagem de linfócitos, neutrófilos e monócitos. O número de eritrócitos foi influenciado $(\mathrm{p}<0,05)$ pela adição de levedura autolisada e zinco nas dietas. Após o estímulo pelo frio o maior prejuízo na eritropoiese ocorreu nos peixes que receberam dietas 0,795:79,50 (Lev:Zn) e 14:1.400 (Lev:Zn). A ausência dos nutrientes-testes determinou queda significativa no hematócrito, leucócitos e proteína plasmática total. O estresse pelo frio determina leucopenia, linfopenia, neutrofilia e monopenia.

PALAVRAS-CHAVES: Estresse, hematologia, minerais, Oreochromis niloticus, saúde, pró-nutriente.

\section{ABSTRACT}

\section{HEMATOLOGICAL PARAMETERS OF NILE TILAPIA: EFFECT OF DIET AND COLD STRESS}

Hematological parameters of Nile tilapia fed diets supplemented with increasing levels of autolised yeast and zinc, before and after cold stress, were analyzed. The diets were formulated to contain $32.0 \% \mathrm{DP}$ and $3,240 \mathrm{kcal} / \mathrm{kg}$ DE with increasing levels of autolised yeast $(\%)$ and zinc $(\mathrm{mg} / \mathrm{kg})$, as: 0.0:0.0; 0.0:79.5; 2.0:0.0; 0.795:79.5; 2.0:200; 4.0:400; 6.0:600; 12.0:1.200; 14.0:1400 . In phase I, 135 fingerlings were distributed into 27 501-aquaria and fed ad libitum four times a day during 128 days $\left(26^{\circ} \mathrm{C}\right)$. After that, phase II began and nine fish from each treatment were transferred to 27401 -aquaria (three/aquarium) and submitted to cold temperature $\left(13.0^{\circ} \mathrm{C}\right)$ during seven days. Before and after cold stress, the following parameters were evaluated: erythrocytes number, hematocrit, hemoglobin, corpuscular volume, mean corpuscular volume, total plasmatic protein, total leucocytes, lymphocytes, neutrophils and monocytes percentage. The number of erythrocytes was significantly influenced by the addition of autolised yeast and zinc to the diets. After cold stress, fish fed diets supplemented with 0.795:79.50 (Lev:Zn) and 14:1400 (Lev:Zn) presented impaired erythrocyte synthesis. Absence of test nutrients determined significant decrease in hematocrit, total leukocyte and total plasmatic protein. Cold stress determines leukopenia, lymphopenia, neutrophylia and monopenia.

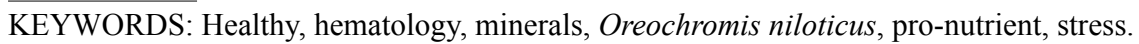




\section{INTRODUÇÃO}

Os pró-nutrientes, por melhorarem o desempenho produtivo e o sistema de defesa, e os minerais, por participarem de diversas funções enzimáticas, tornaram-se objetos de estudos na área de nutrição e saúde animal. Segundo BARROS et al. (2009), o novo conceito de balanceamento de rações considera que, além de nutrir o animal, visando o máximo desempenho, é necessário nutrir, ainda, seu sistema de defesa. Tal prática, além de possibilitar as respostas zootécnicas almejadas e a saúde dos peixes, permite que se obtenha maior resistência orgânica para superar a ação de agentes estressores, componentes inevitáveis sob condições intensivas de cultivo.

Alevedura apresenta, em sua composição, estimulantes naturais que proporcionam melhora no metabolismo (TOVAR et al., 2002) e bem-estar animal (BUTOLO, 2002), sendo uma fonte alternativa de pró-nutriente (LI \& GATLIN III, 2004; PEZZATO et al., 2006). Entretanto, quando utilizada como única fonte proteica em dietas para peixes, tem resultado em prejuízo ao desenvolvimento e ao metabolismo, além de anemia microcítica hipocrômica (SÁNCHEZ-MUNIZ et al., 1982).

Pesquisas com zinco têm demonstrado melhora no desempenho produtivo (WATANABE et al., 1997; WATANABE et al., 2004; SÁ et al., 2004) e na saúde dos peixes (HISANO et al., 2007b). Em condições de deficiência desse mineral, relataram-se baixos índices de ganho de peso, piora na conversão alimentar e menor ingestão diária de alimento (HIDALGO et al., 2002), podendo, ainda, prejudicar as funções dos hormônios da tireoide (FREAKE et al., 2001; ROSSI et al., 2001) e a eritropoiese (SÁ et al., 2004). Foi também relatada a interação antagônica entre o zinco e outros minerais de mesmo caráter iônico bivalente (SANDSTRÖN, 2001; SÁ et al., 2005).

A ação benéfica aos processos metabólicos da levedura (LI \& GATLIN III, 2004) e do zinco (SÁ et al., 2005) em peixes evidencia a necessidade de melhor investigação. No caso da levedura, pelas prováveis ações na microbiota intestinal dos peixes (RUNSEY et al., 1992), e do zinco, por apresentar-se como promotor de crescimento nos animais (ROSSI et al., 2001).

Dessa forma, o presente experimento objetivou avaliar a influência da suplementação de levedura autolisada e zinco e suas respectivas relações nas dietas, sobre os parâmetros hematológicos em alevinos de tilápia-do-nilo (Oreochromis niloticus) submetidos ao estímulo pelo frio.

\section{MATERIAL e MÉTODOS}

O experimento foi realizado na Faculdade de Medicina Veterinária e Zootecnia, Unesp, DMNA, Laboratório de Nutrição de Organismos Aquáticos - AquaNutri -, Unidade integrada ao CAUNESP. O experimento constou de duas fases: anterior e posterior ao estímulo pelo frio.

Fase I - anterior ao estímulo pelo frio

Após período de adaptação de dez dias às condições experimentais, 135 alevinos com peso médio de 7,27 $\pm 0,19 \mathrm{~g}$ foram distribuídos aleatoriamente em 27 aquários retangulares com capacidade de 50L cada, numa densidade de cinco peixes/aquário. A estrutura experimental incluía filtro biológico, sistema de recirculação e aeração. A renovação média de água foi de $13,19 \mathrm{~mL} / \mathrm{s}$ ou renovação completa em 63,20 minutos. Manteve-se a temperatura da água dentro da faixa de conforto para a espécie, $26,0 \pm 1,0^{\circ} \mathrm{C}$, sendo aferida às $8 \mathrm{~h} 00$ e $17 \mathrm{~h} 00$. Fez-se avaliação semanal do pH e do teor de oxigênio dissolvido da água por meio de peagâmetro e oxímetro digital e, quinzenalmente, com kits comerciais para controle de amônia e nitrito e a alcalinidade por soluções-padrões, respectivamente.

O delineamento experimental adotado foi o inteiramente casualizado com nove dietas contendo níveis de levedura autolisada em percentual e zinco em $\mathrm{mg} / \mathrm{kg}$ de dieta, tais como $0,0: 0,0 ; 0,795: 79,5$; $2,0: 200 ; 4,0: 400 ; 6,0: 600 ; 12,0: 1.200$ e 14,0:1.400, respectivamente. Confrontaram-se esses tratamentos com outros dois tratamentos, um contendo 79,50 mg de zinco suplementar/kg ausente da suplementação de levedura autolisada, como determinado por SÁ et al. (2004), e o outro suplementado com $2,0 \%$ de levedura autolisada ausente de zinco, fundamentado nos resultados obtidos por HISANO et al. (2007a) (Tabela 1). Como fonte de zinco, utilizou-se o sulfato de zinco heptaidratado, qualidade comercial analisada de 21,0\%. A concentração de zinco nas dietas (Tabela 1) foi calculada com base na análise realizada sobre o composto de zinco utilizado para suplementação deste micromineral nas dietas. 
TABELA 1. Composição percentual das dietas experimentais contendo níveis crescentes de levedura autolisada (Lev) e zinco (Zn) para a tilápia-do-nilo ${ }^{1}$

\begin{tabular}{|c|c|c|c|c|c|c|c|c|c|}
\hline \multirow[t]{2}{*}{ Ingredientes } & \multicolumn{9}{|c|}{ Lev: $Z n^{2}$} \\
\hline & $0,0: 0,0$ & $0,0: 79,5$ & $2,0: 0,0$ & $0,795: 79,5$ & $2,0: 200$ & $4,0: 400$ & $6,0: 600$ & $12,0: 1200$ & $14,0: 1400$ \\
\hline Farelo de soja & 58,50 & 58,50 & 58,00 & 58,00 & 57,00 & 56,00 & 54,50 & 48,00 & 45,00 \\
\hline Glúten de milho & 5,78 & 5,78 & 5,60 & 5,88 & 6,15 & 6,37 & 6,72 & 9,32 & 10,80 \\
\hline Fubá de milho & 7,00 & 7,00 & 6,60 & 7,00 & 7,00 & 6,56 & 6,13 & 6,30 & 6,30 \\
\hline Farelo de trigo & 7,50 & 7,50 & 5,90 & 7,30 & 7,30 & 5,75 & 5,80 & 4,90 & 4,50 \\
\hline Quirera de arroz & 13,33 & 13,29 & 13,75 & 13,06 & 12,46 & 12,91 & 12,21 & 10,00 & 9,59 \\
\hline Levedura autolisada & 0,00 & 0,00 & 2,00 & 0,80 & 2,00 & 4,00 & 6,00 & 12,00 & 14,00 \\
\hline Cloreto de sódio & 0,50 & 0,50 & 0,50 & 0,50 & 0,50 & 0,50 & 0,50 & 0,50 & 0,50 \\
\hline Fosfato bicálcico & 3,70 & 3,70 & 3,70 & 3,70 & 3,65 & 3,60 & 3,50 & 3,40 & 3,30 \\
\hline Calcário calcítico & 0,00 & 0,00 & 0,00 & 0,00 & 0,00 & 0,00 & 0,08 & 0,15 & 0,18 \\
\hline Sulfato de zinco ${ }^{3}$ & 0,00 & 0,04 & 0,00 & 0,04 & 0,10 & 0,19 & 0,29 & 0,57 & 0,67 \\
\hline Celulose & 1,85 & 1,85 & 2,05 & 1,89 & 2,00 & 2,23 & 2,40 & 2,95 & 3,23 \\
\hline Óleo de soja & 0,60 & 0,60 & 0,67 & 0,60 & 0,60 & 0,65 & 0,64 & 0,59 & 0,56 \\
\hline L-lisina & 0,30 & 0,30 & 0,30 & 0,30 & 0,30 & 0,30 & 0,30 & 0,37 & 0,42 \\
\hline DL-Metionina & 0,57 & 0,57 & 0,57 & 0,57 & 0,57 & 0,57 & 0,56 & 0,53 & 0,52 \\
\hline Triptofano & 0,00 & 0,00 & 0,00 & 0,00 & 0,00 & 0,00 & 0,00 & 0,05 & 0,06 \\
\hline L-Treonina & 0,25 & 0,25 & 0,25 & 0,25 & 0,25 & 0,25 & 0,25 & 0,25 & 0,25 \\
\hline Suplemento & 0,10 & 0,10 & 0,10 & 0,10 & 0,10 & 0,10 & 0,10 & 0,10 & 0,10 \\
\hline Antioxidante $(\mathrm{BHT})^{5}$ & 0,02 & 0,02 & 0,02 & 0,02 & 0,02 & 0,02 & 0,02 & 0,02 & 0,02 \\
\hline Total & 100,00 & 100,00 & 100,00 & 100,00 & 100,00 & 100,00 & 100,00 & 100,00 & 100,00 \\
\hline
\end{tabular}

1 Formulação das dietas realizadas segundo: NRC (1993); PEZZATO et al. (2002); GONÇALVES et al. (2004; 2005); GUIMARÃES et al. (2008a, b).

2 Níveis de levedura autolisada em porcentual e zinco em $\mathrm{mg} / \mathrm{kg}$ de dieta.

3 Fonte comercial de sulfato de zinco heptaidratado [ZnSO4(7H2O)] qualidade comercial 21,0\% de zinco.

4 Suplemento vitamínico e mineral ausente de zinco (níveis de garantia por $\mathrm{kg}$ do produto): vit. $\mathrm{A}=1.200 .000 \mathrm{UI}$; vit. D3=200.000 UI; vit. $\mathrm{E}=12.000$ $\mathrm{mg}$; vit. K3 = $2.400 \mathrm{mg}$; vit. $\mathrm{B} 1=4.800 \mathrm{mg}$; vit. $\mathrm{B} 2=4.800 \mathrm{mg}$; vit. $\mathrm{B} 6=4.000 \mathrm{mg}$; vit. $\mathrm{B} 12=4.800 \mathrm{mg}$; ácido fólico = $1.200 \mathrm{mg}$; pantotenato de cálcio $=12.000 \mathrm{mg}$; vit. $\mathrm{C}=48.000 \mathrm{mg}$; biotina $=48 \mathrm{mg}$; colina $=65.000 \mathrm{mg}$; niacina $=24.000 \mathrm{mg}$; ferro $=10.000 \mathrm{mg} ;$ cobre $=600 \mathrm{mg}$; manganês $=4.000 \mathrm{mg}$; iodo $=20 \mathrm{mg}$; cobalto $=2 \mathrm{mg}$ e selênio $=20 \mathrm{mg}$.

5 Antioxidante $(\mathrm{BHT})=$ Butil hidróxi tolueno.

Nesta fase os peixes foram alimentados ad libitum, quatro vezes ao dia, às 8:00h, 11:00h, 14:00h e 17:00h, pelo período de 128 dias, com as dietas experimentais, as quais foram armazenadas em freezer a $-4,0^{\circ} \mathrm{C}$. Ao final dessa fase experimental, os peixes apresentavam peso médio de 117,92 $\pm 25,47 \mathrm{~g}$. Quando necessário, realizaram-se limpeza dos aquários e das demais estruturas por sifonagem, para a retirada do acúmulo de resíduos das fezes.

As avaliações hematológicas e metabólicas foram realizadas aos $128^{\circ}$ dias, para investigar a influência das dietas, e após sete dias ao estímulo pelo frio, 
para evidenciar possível ação das dietas com relação ao estresse provocado aos peixes. A coleta de sangue foi efetuada no vaso caudal com seringa de $1,0 \mathrm{~mL}$ banhada em anticoagulante EDTA $(3,0 \%)$ nos peixes anestesiados em benzocaína (100 $\mathrm{mg} / \mathrm{L}$ de água).

Procedeu-se à contagem do número de eritrócitos e leucócitos totais pelo método do hemocitômetro em câmara de Neubauer, utilizando-se azul de toluidina a $0,01 \%$ em pipeta de Thoma como solução diluente e corante. A diferenciação dos leucócitos foi realizada em esfregaço sanguíneo corado com MayGrünwald Giemsa.

A taxa de hemoglobina foi determinada pelo método da cianometahemoglobina, utilizando-se kit de determinação fotocolorimétrica (Analisa Diagnóstica $\left.{ }^{\circledR}\right)$, segundo COLLIER (1944). Para determinação da porcentagem de hematócrito, utilizou-se centrífuga para micro-hematócrito numa rotação de 5.000 rpm durante cinco minutos (GOLDENFARB et al., 1971) e para mensuração da proteína plasmática empregou-se refratômetro manual de Goldenberg. As variáveis antes apresentadas foram avaliadas segundo as técnicas descritas por JAIN (1986). Posteriormente a essas análises, procedeu-se ao cálculo dos seguintes índices hematimétricos: volume corpuscular médio [VCM $=($ Htc $\times 10)$ /eritrócitos $]$ e concentração de hemoglobina corpuscular média $[\mathrm{CHCM}=(\mathrm{Hb} / \mathrm{Htc})$ $x$ 100], segundo WINTROBE (1934).

Realizou-se a contagem diferencial de leucócitos nas extensões em lâminas. Estas foram previamente limpadas com detergente e água, e desengorduradas com éter etílico PA e acetona PA, sendo seca com auxílio de gaze. Devidamente identificadas, foram confeccionadas três lâminas por tratamento, acondicionadas em caixas apropriadas e posteriormente coradas com corantes hematológicos May-Grünwald Giemsa, utilizando-se a técnica descrita por TAVARES-DIAS \& MORAES (2004). Fez-se a contagem diferencial em microscópio com aumento de 100 vezes, contando-se 200 células e estabelecendo-se o percentual de cada componente celular (linfócitos, neutrófilos e monócitos).

Fase II - após estímulo pelo frio

Após as avaliações hematológicas aos $128^{\circ}$ dias, os peixes permaneceram nas estruturas experimentais com o sistema de controle térmico desligado, objetivando baixar gradativamente a temperatura, para posterior mudança dos animais para a sala de desafio. A partir do momento em que a temperatura da água dos aquários de ambas as estruturas experimentais se igualou, nove peixes de cada tratamento foram transferidos para a sala experimental climatizada constituída de 27 aquários de 40L com filtros individualizados e aeração. Distribuíram-se aleatoriamente 81 peixes, na densidade de três peixes/aquário, constituindo cada peixe uma unidade experimental, mantendo-se o mesmo delineamento experimental da Fase I com nove repetições por tratamento.

Após a distribuição dos peixes, a temperatura da água dos aquários foi gradativamente reduzida do conforto térmico para a espécie até $13,0^{\circ} \mathrm{C}$ durante o período experimental de sete dias. Alimentaram-se os animais ad libitum, porém não foi mensurado o alimento consumido. Ao final desse período, procedeuse à avaliação dos mesmos parâmetros hematológicos da Fase I. Dividiu-se o estudo em duas fases, para avaliação da influência dos nutrientes suplementados às dietas antes e após ao estresse provocado com o estímulo pelo frio aos peixes com relação às variáveis hematológicas e metabólicas destes.

\section{Análise estatística}

Os dados foram submetidos à técnica de análises multivariadas pelo modelo de medidas repetidas, considerando nove grupos independentes, complementada com os intervalos de confiança simultâneo (JOHNSON \& WICHERN, 1992). Diferenças entre médias foram reportadas como significativas ao nível de 5,0\%. Realizou-se a comparação entre grupos pela análise de contrastes ortogonais.

\section{RESULTADOS E DISCUSSÃO}

Os parâmetros de qualidade de água, monitorados na Fase I, mostraram-se dentro do considerado adequado para manutenção da condição de saúde dos peixes, segundo BOYD (1990).

O número de eritrócitos foi significativamente influenciado pelos níveis de suplementação de levedura e zinco nas dietas (Tabela 2). Na fase I, níveis elevados de suplementação de zinco (1.200 e $1.400 \mathrm{mg} / \mathrm{kg}$ dieta) na dieta determinaram os menores valores de eritrócitos nos peixes, independente 
do nível de suplementação de levedura autolisada, sendo o mesmo resultado observado nos peixes que receberam a dieta isenta de suplementação de zinco e que continha $2,0 \%$ de levedura autolisada e naquela suplementada com 0,795Lev:79,5Zn (Lev:Zn; levedura autolisada em percentual e zinco em $\mathrm{mg} / \mathrm{kg}$ de dieta, respectivamente).

A combinação de levedura autolisada e zinco nas dietas não determinou melhora no perfil hematológico dos peixes. Resultados semelhantes foram anteriormente descritos por HISANO et al. (2007b), com a suplementação de até $3,0 \%$ de levedura autolisada na dieta para a tilápia-do-nilo, porém o autor ressaltou tendência de aumento nos valores de eritrócitos. Alterações positivas no perfil hematológico de peixes foram anteriormente descritas por LI \& GATLIN III (2003) para o híbrido Striped bass, com a inclusão de levedura Saccharomyces cerevisiae na dieta $(1,0 \% ; 2,0 \%$ e $4,0 \%)$, destacando-se tendência de melhora na saúde dos peixes com a suplementação de 1,0\%, o que foi observado por meio de parâmetros imunológicos. Ação benéfica na saúde dos peixes com a suplementação dietária de levedura e zinco foi também descrita por HISANO et al. (2007b).

Os valores sanguíneos deste estudo demonstraram que a dieta ausente de suplementação de levedura autolisada e zinco (Tabela 2) apresentou níveis nutricionais disponíveis para suprir as exigências da tilápia-do-nilo, determinando status nutricional adequado. Isso pode explicar os valores próximos obtidos com a suplementação de levedura autolisada, zinco e levedura autolisada e zinco.

Melhora significativa na eritropoiese foi observada por SÁ et al. (2004), com a suplementação de níveis de 0,0 a 400,0 mg de $\mathrm{Zn} / \mathrm{kg}$ na dieta para tilápia-do-nilo. Trata-se de resultados que não ficaram claramente evidenciados neste estudo. $\mathrm{O}$ zinco presente nas enzimas anidrase carbônica e superóxido dismutase (HAMBIDGE, 1986) tem função de proteção e manutenção da integridade da membrana dos eritrócitos (O’DELL et al., 1987), sendo que a deficiência deste resultou em baixa contagem de células (KRAUS et al., 1997).

A suplementação dos níveis acima da exigência nutricional poderia determinar inter-relação metabólica desse mineral com o ferro (DEVLIN, 1997;
SÁ et al., 2005) e comprometer o metabolismo dos peixes, com prejuízos na síntese de hemoglobina pela possível inibição da transferência do ferro da ferroquelatase a protoporfirina IX e consequente comprometimento da formação do grupo heme (DEVLIN, 1997). Entretanto, são necessárias informações mais aprofundadas para confirmar tal hipótese.

Considerando-se a ação benéfica de oligossacarídeos não digestíveis no estímulo à absorção de diversos minerais (SCHOLZ-AHRENS et al., 2001) e na capacidade de melhora da resposta inata (ORTUÑO et al., 2002; Li e GATLIN III, 2004; SELVARAJ et al., 2005) exercida pelo glucano que compõe em torno de 7,7\% da célula de levedura (CABIB et al., 1982; RUNSEY et al., 1992), seria esperado que em níveis baixos de inclusão (pró-nutrientes) esta viesse a ter efeito benéfico na saúde dos peixes. Essa hipótese pode ser observada pela tendência de melhora nos parâmetros sanguíneos com a inclusão de levedura autolisada, principalmente quando os animais sofreram estresse pelo frio.

Após o estresse pelo frio, os peixes que demonstraram maior prejuízo na eritropoiese foram os que receberam dietas suplementadas com 0,795Lev:79,50Zn e 14,0Lev:1.400Zn, valores esses condizentes com a condição anterior ao estresse. A menor porcentagem de hematócrito foi igualmente determinada nos peixes desses mesmos tratamentos, o que também se observou para a taxa de hemoglobina. Já a menor concentração de proteína plasmática total foi observada nos peixes que receberam dieta suplementada com 14,0Lev:1.400Zn de levedura autolisada e zinco, respectivamente.

A avaliação do perfil hematológico é considerada ferramenta importante na análise do estado de saúde dos peixes (NOGA, 2000; FALCON et al., 2007), que, estimulados, seja pelo estresse causado por infecções e/ou variações ambientais, podem responder positiva ou negativamente às dietas fornecidas. Neste estudo, observou-se que, embora na fase I a ausência desses nutrientes $(0,0 \mathrm{Lev}: 0,0 \mathrm{Zn})$ na dieta tenha mantido os parâmetros hematológicos dentro do considerado normal em condições adequadas de temperatura, abaixo do conforto térmico, a exigência de nutrientes pode ter sido maior, condição refletida na queda da porcentagem de células vermelhas $(\mathrm{P}<0,05)$. 


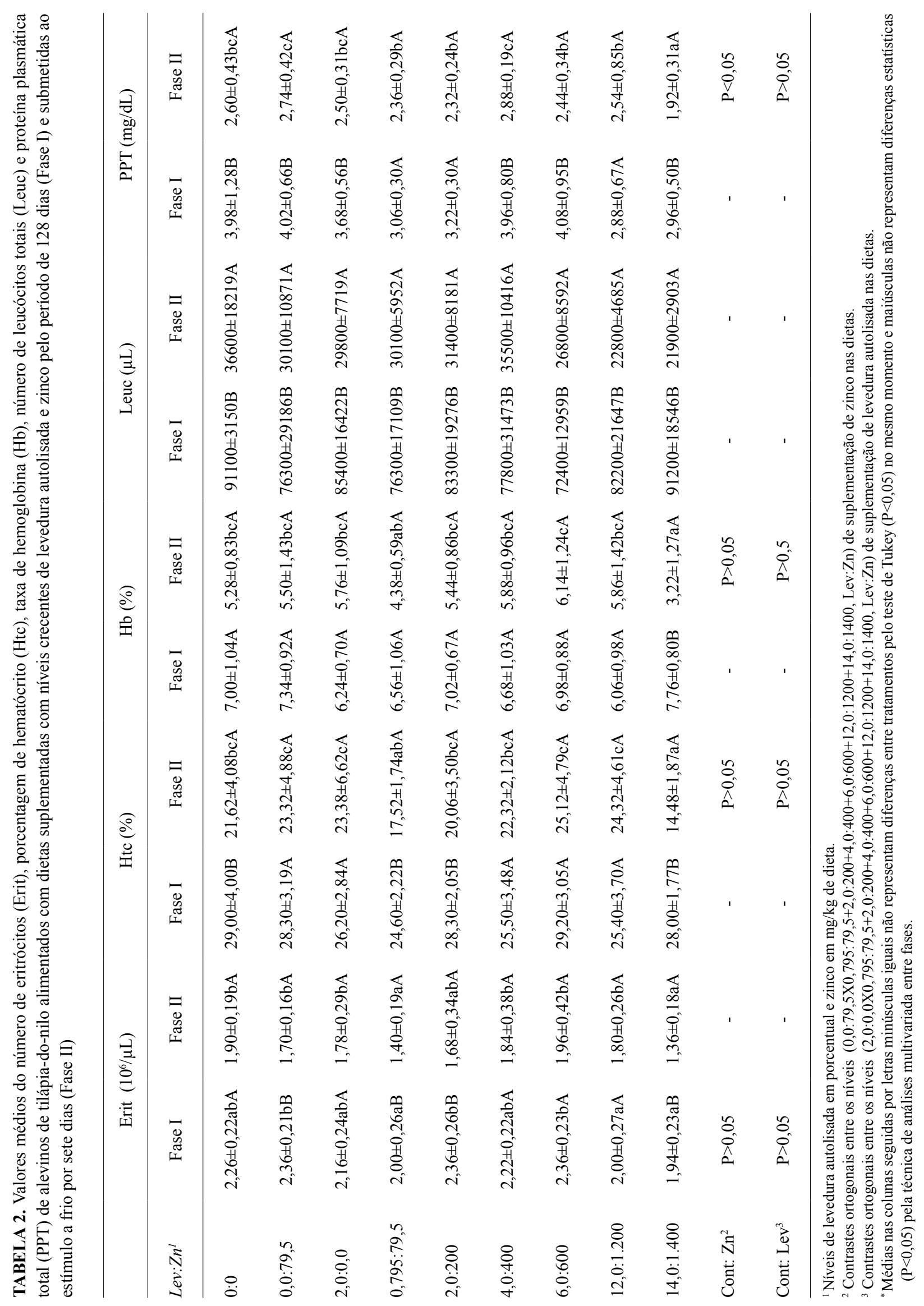


Embora não de forma significativa, observouse redução de $15,92 \%$ no número de eritrócitos; $24,57 \%$ na taxa de hemoglobina e $11,50 \%$ no VCM. A avaliação do leucograma e da concentração de proteína plasmática total corroborou com a condição de saúde menos favorável para os peixes deste tratamento $(0,0 \mathrm{Lev}: 0,0 \mathrm{Zn})$. O aumento da porcentagem de neutrófilos traduz o esforço do organismo em vencer possíveis condições patogênicas instaladas em função da queda de resistência do organismo. No entanto, VRUWINK et al. (1993) descreveram que a deficiência de zinco prejudica a função fagocítica do neutrófilo. Os resultados relatados após o estresse pelo frio foram anteriormente descritos por FALCON et al. (2007, 2008).

Comparando-se a condição anterior e posterior ao estímulo pelo frio observou-se que a ausência dos nutrientes-testes determinou queda significativa na porcentagem de hematócrito, número de leucócitos totais e proteína plasmática total. A não suplementação de levedura autolisada determinou queda na síntese de células vermelhas, número de leucócitos totais e proteína plasmática total. Já a ausência de suplementação de zinco determinou prejuízo signifi- cativo na síntese de células brancas totais e proteína plasmática total.

Alteração significativa no volume do eritrócito (VCM) (Tabela 3) foi observada somente nos peixes alimentados com a dieta suplementada com 14,0Lev:1.400Zn de levedura autolisada e zinco, respectivamente. Esse menor valor reflete a taxa de hemoglobina e a porcentagem de hematócrito também encontradas nesses animais.

$\mathrm{Na}$ fase anterior ao estresse pelo frio, não foi observada influência dos nutrientes-testes na síntese dos diferentes tipos de leucócitos: linfócito, neutrófilo e monócito (Tabela 4). Porém, após o estresse, todos os três tipos avaliados foram significativamente alterados. Observou-se a menor porcentagem de linfócito nos peixes arraçoados com a dieta suplementada com 6,0Lev:600Zn. Registraram-se, no entanto, para esses animais, os maiores valores de neutrófilo e monócitos. A suplementação dietária 4,0Lev:400Zn determinou a maior porcentagem de linfócitos. Já as menores porcentagens de neutrófilo e monócito foram observadas para $0,795 \mathrm{Lev}: 79,50 \mathrm{Zn}$ e $12,0 \mathrm{Lev}: 1200 \mathrm{Zn}$, respectivamente.

TABELA 3. Valores médios de volume corpuscular médio (VCM) e concentração de hemoglobina corpuscular média (CHCM) de alevinos de tilápia-do-nilo alimentados com dietas suplementadas com níveis crescentes de levedura autolisada e zinco pelo período de 128 dias (Fase I) e submetidas ao estímulo pelo frio por sete dias (Fase II)

\begin{tabular}{|c|c|c|c|c|}
\hline \multirow[b]{2}{*}{ Lev: $: n^{l}$} & \multicolumn{2}{|c|}{ VCM (fL) } & \multicolumn{2}{|c|}{ CHCM (\%) } \\
\hline & Fase I & Fase II & Fase I & Fase II \\
\hline $0: 0$ & $128,44 \pm 8,48 \mathrm{~A}$ & $113,62 \pm 17,67 \mathrm{~A}$ & $24,10 \pm 1,07$ & $24,58 \pm 2,99$ \\
\hline $0,0: 79,5$ & $121,08 \pm 16,25 \mathrm{~A}$ & $137,00 \pm 24,82 \mathrm{~A}$ & $26,00 \pm 2,39$ & $23,48 \pm 4,34$ \\
\hline $2,0: 0,0$ & $123,54 \pm 16,07 \mathrm{~A}$ & $132,10 \pm 27,04 \mathrm{~A}$ & $24,02 \pm 3,60$ & $25,30 \pm 3,93$ \\
\hline $0,795: 79,5$ & $124,54 \pm 12,29 \mathrm{~A}$ & $124,78 \pm 10,83 \mathrm{~A}$ & $26,72 \pm 4,38$ & $25,08 \pm 2,04$ \\
\hline $2,0: 200$ & $120,28 \pm 7,08 \mathrm{~A}$ & $122,08 \pm 22,57 \mathrm{~A}$ & $24,76 \pm 1,66$ & $27,14 \pm 0,68$ \\
\hline $4,0: 400$ & $115,66 \pm 9,82 \mathrm{~A}$ & $124,98 \pm 23,46 \mathrm{~A}$ & $26,32 \pm 1,55$ & $26,34 \pm 3,25$ \\
\hline $6,0: 600$ & $124,80 \pm 19,83 \mathrm{~A}$ & $128,98 \pm 19,93 \mathrm{~A}$ & $23,86 \pm 2,15$ & $24,62 \pm 3,00$ \\
\hline $12,0: 1200$ & $127,26 \pm 11,13 \mathrm{~A}$ & $135,14 \pm 14,44 \mathrm{~A}$ & $23,94 \pm 2,13$ & $24,08 \pm 3,96$ \\
\hline $14,0: 1400$ & $144,32 \pm 9,92 \mathrm{~B}$ & $108,04 \pm 3,56 \mathrm{~A}$ & $27,66 \pm 1,63$ & $22,18 \pm 7,49$ \\
\hline
\end{tabular}

${ }^{1}$ Níveis de levedura autolisada em porcentual e zinco em $\mathrm{mg} / \mathrm{kg}$ de dieta.

${ }^{*}$ Médias nas linhas seguidas por letras maiúsculas iguais não representam diferenças estatísticas $(\mathrm{P}<0,05)$ entre fases pela técnica de análises multivariadas. 
TABELA 4. Porcentagem média do número de linfócitos (Linf), neutrófilos (Neut) e monócitos (Mon) de alevinos de tilápia-do-nilo alimentados com dietas suplementadas com níveis crescentes de levedura autolisada e zinco pelo período de 128 dias (Fase I) e submetidas ao estímulo pelo frio por sete dias (Fase II)

\begin{tabular}{|c|c|c|c|c|c|c|}
\hline \multirow[b]{2}{*}{ Lev: $Z^{1}$} & \multicolumn{2}{|c|}{ Linf } & \multicolumn{2}{|c|}{ Neut } & \multicolumn{2}{|c|}{ Mon } \\
\hline & Fase I (\%) & Fase II $(\%))$ & Fase I (\%) & Fase II (\%) & Fase I (\%) & Fase II (\%) \\
\hline $0,0: 0,0$ & $77,60 \pm 15,36 \mathrm{~A}$ & $62,75 \pm 8,02 \mathrm{ce} A$ & $15,00 \pm 12,34 a$ & $33,38 \pm 9,59 \mathrm{abcB}$ & $7,40 \pm 4,74 \mathrm{~A}$ & $3,88 \pm 1,78 \mathrm{abcA}$ \\
\hline $0,0: 79,5$ & $89,00 \pm 7,20 \mathrm{~A}$ & $71,00 \pm 4,78$ defA & $6,50 \pm 4,43 a$ & $26,00 \pm 6,09 \mathrm{abB}$ & $4,50 \pm 3,10 \mathrm{~A}$ & $2,63 \pm 2,53 \mathrm{abA}$ \\
\hline $2,0: 0,0$ & $94,30 \pm 7,40 \mathrm{~B}$ & $49,30 \pm 14,92 \mathrm{abA}$ & $10,00 \pm 6,04 \mathrm{a}$ & $44,90 \pm 14,39 \mathrm{cdB}$ & $5,40 \pm 2,16 \mathrm{~A}$ & $5,20 \pm 1,99 \mathrm{bcdA}$ \\
\hline $0,795: 79,5$ & $83,60 \pm 11,48 \mathrm{~A}$ & $77,40 \pm 8,47 \mathrm{fA}$ & $10,80 \pm 9,54 \mathrm{a}$ & $19,60 \pm 8,97 \mathrm{aA}$ & $5,40 \pm 2,30 \mathrm{~A}$ & $3,00 \pm 1,87 \mathrm{abA}$ \\
\hline $2,0: 200$ & $82,00 \pm 8,49 \mathrm{~B}$ & $55,13 \pm 7,21 \mathrm{bcA}$ & $12,20 \pm 6,18 \mathrm{a}$ & $40,25 \pm 5,49 \mathrm{cB}$ & $5,80 \pm 3,05 \mathrm{~A}$ & $4,63 \pm 1,98 \mathrm{bcdA}$ \\
\hline $4,0: 400$ & $76,80 \pm 12,42 \mathrm{~A}$ & $76,10 \pm 12,97 \mathrm{fA}$ & $16,20 \pm 9,14 \mathrm{a}$ & $25,20 \pm 13,17 \mathrm{abA}$ & $6,90 \pm 4,02 \mathrm{~A}$ & $2,70 \pm 1,79 \mathrm{abA}$ \\
\hline $6,0: 600$ & $84,70 \pm 9,87 \mathrm{~B}$ & $36,70 \pm 23,06 \mathrm{aA}$ & $10,90 \pm 7,70 \mathrm{a}$ & $55,20 \pm 20,32 \mathrm{~dB}$ & $4,40 \pm 4,11 \mathrm{~A}$ & $7,80 \pm 5,77 \mathrm{dA}$ \\
\hline $12,0: 1200$ & $79,10 \pm 11,33 \mathrm{~A}$ & $69,63 \pm 10,17$ defA & $14,90 \pm 8,13 \mathrm{a}$ & $29,13 \pm 9,99 \mathrm{abA}$ & $6,00 \pm 3,76 \mathrm{~B}$ & $1,13 \pm 0,41 \mathrm{aA}$ \\
\hline $14,0: 1400$ & $78,80 \pm 9,35 \mathrm{~B}$ & $59,60 \pm 6,94 \mathrm{bcdA}$ & $15,00 \pm 8,80 \mathrm{a}$ & $34,40 \pm 5,52 \mathrm{bcB}$ & $5,80 \pm 1,20 \mathrm{~A}$ & $6,00 \pm 3,16 \mathrm{cdA}$ \\
\hline Cont $^{2}: \mathrm{Zn}$ & - & $\mathrm{P}>0,05$ & - & $\mathrm{P}>0,05$ & - & $\mathrm{P}>0,05$ \\
\hline Cont $^{3}:$ Lev & - & $\mathrm{P}>0,05$ & - & $\mathrm{P}>0,05$ & - & $\mathrm{P}>0,05$ \\
\hline
\end{tabular}

${ }^{1}$ Níveis de levedura autolisada em porcentual e zinco em $\mathrm{mg} / \mathrm{kg}$ de dieta.

${ }^{2}$ Contrastes ortogonais entre os níveis $(0,0: 79,5 \times 0,795: 79,5+2,0: 200+4,0: 400+6,0: 600+12,0: 1200+14,0: 1400$, Lev:Zn) de suplementação de zinco nas dietas.

${ }^{3}$ Contrastes ortogonais entre os níveis $(2,0: 0,0 X 0,795: 79,5+2,0: 200+4,0: 400+6,0: 600+12,0: 1200+14,0: 1400$, Lev:Zn) de suplementação de levedura autolisada nas dietas.

"Médias nas colunas seguidas por letras minúsculas iguais não representam diferenças entre tratamentos pelo teste de Tukey $(\mathrm{P}<0,05)$ no mesmo momento e maiúsculas não representam diferenças estatísticas $(\mathrm{P}<0,05)$ pela técnica de análises multivariada entre fases.

Neste estudo, os peixes que receberam dieta ausente de suplementação de levedura autolisada e zinco não desenvolveram anemia, embora a queda na taxa de hemoglobina e na porcentagem de hematócrito indique tendência desse quadro hematológico. No entanto, os peixes que receberam a dieta suplementada com 0,795Lev:79,50Zn a 14,0Lev:1.400Zn, respectivamente, desenvolveram quadro de anemia microcítica hipocrômica, característica da deficiência de ferro. Observaram-se níveis abaixo do normal para peixes hígidos no número de eritrócitos, porcentagem de hematócrito e taxa de hemoglobina. Resultados semelhantes foram observados por SÁ et al. (2005), que, ao fornecerem dietas práticas e purificadas para alevinos de tilápia-do-nilo, observaram influência do zinco no metabolismo do ferro. Essa ação pode demonstrar a possível inter-relação dos minerais disponíveis, principalmente zinco-ferro, ao nível celular, e dos níveis de nitrogênio não proteico advindos da suplementação de levedura autolisada. Nos demais tratamentos, os peixes podem ter sustentado o perfil hematológico em função da reserva corpórea de ferro, indicando possivelmente que o nível de zinco suplementado não estaria, no tempo avaliado, influenciando significativamente o metabolismo do ferro. A possível ação da levedura na eritropoiese foi descrita por SANCHEZ-MUNIZ et al. (1982), que, ao substituírem a proteína da dieta para truta arco-íris pela levedura Hansenula anômala, observaram possível ação degenerativa dos eritrócitos.

O prejuízo na manutenção dos parâmetros hematológicos dos peixes sob condições de baixa temperatura (estresse crônico) foi anteriormente descrito por FALCON et al. (2007), em avaliação do estado de higidez da tilápia-do-nilo alimentada com dietas contendo suplementação de vitamina $\mathrm{C}$ e lipídeos. Os valores determinados por esses autores não atingiram níveis tão baixos quanto os do presente experimento. Vale ressaltar que o estresse deste estudo foi agudo 
com menor temperatura, quando comparado ao estudo citado. NOGA (2000) relatou que as respostas hematológicas dos peixes, aclimatados e submetidos à condição crônica de redução da temperatura, são menores.

Os peixes expostos à baixa temperatura apresentam redução do metabolismo, o que pode afetar a condição fisiológica e determinar redução do perfil hematológico. Observaram-se alterações significativas principalmente nas células do sistema de defesa, com leucopenia independente da suplementação ou não de levedura autolisada e zinco e, ainda, linfopenia, neutrofilia e monopenia. Quadro de leucopenia sob condições de estresse por temperatura foi anteriormente descrito por DUNN et al. (1989), para Carassius auratus, e por FALCON et al. (2008), para tilápia-do-nilo, os quais observaram ainda, como as respostas deste estudo, aumento significativo do número de neutrófilos. Dessa forma, é certo o prejuízo exercido pelo estresse pelo frio às condições de higidez dos peixes, mesmo em condições nutricionais adequadas.

\section{CONCLUSÕES}

A suplementação de levedura autolisada, zinco ou levedura autolisada e zinco nas dietas não reflete um padrão de melhora do perfil hematológico; níveis elevados de levedura autolisada e zinco na dieta determinam condições subótimas de saúde; o estresse pelo frio determina leucopenia, linfopenia, neutrofilia e monopenia.

\section{AGRADECIMENTOS}

À Fundação de Amparo à Pesquisa do Estado de São Paulo, FAPESP, pela bolsa de estudo concedida (Processo 05/52232-6), à Usina São Luis, em nome do supervisor de Produção Industrial, Marcos F. Zimak, pelo apoio científico, ao Laboratório de Química do Instituto de Biociências, pelo auxilio nas análises, e ao Prof. Dr. Carlos Roberto Padovani, pelas análises estatísticas.

\section{REFERÊNCIAS}

BARROS, M. M.; RANZANI, P. M. J. T.; PEZZATO, L. E.; FALCON, D. R.; GUIMARÃES, I. G. Hematological response and growth performance of Nile tilapia fed diets containing folic acid. Aquaculture Research, v. 40, p. 895-903, 2009.
BOYD, C. Water quality in ponds for aquaculture. Alabama: Birmingham Publiscing, 1990. 482 p.

BUTOLO, J. E. Qualidade de ingredientes na alimentação animal. Campinas, SP: Agro Comunicação, 2002. 430 p.

CABIB, E.; ROBERTS, R.; BOWERS, B.; Synthesis of the yeast cell wall and its regulation. Annual Review Biochemistry, v. 51, p. $763-793,1982$.

COLLIER, H. B. The standardization of blood haemoglobin determinations. Canadian Medical Assistance Journal, v. 50, p. $550-552,1944$.

DEVLIN, T. M. Textbook of biochemistry with clinical correlations. Wiley-Liss, New York: John Wiley \& Sons, Inc. Copyright.1997. 1007 p.

DUNN, S. E.; MURAD, A.; HOUSTON, A. H. Leucocyts and leucopoietic capacyt in thermally acclimated goldfish, Carassius auratus L. Journal Fish Biology, v. 34, p. 901-911, 1989.

FALCON, D. R.; BARROS, M. M; PEZZATO, L. E.; NARVÁEZ, W. V.; GUIMARÃES, I. G. Leucograma da tilápia-do-nilo arraçoada com dietas suplementadas com níveis de vitamina $\mathrm{C}$ e lipídeo submetidas a estresse por baixa temperatura. Ciência Animal Brasileira, v. 9, p. 543-551, 2008.

FALCON, D. R.; BARROS, M. M.; PEZZATO, L. E.; VALLE, J. B. Lipídeo e vitamina $\mathrm{C}$ em dietas preparatórias de inverno para tilápias-do-nilo. Revista Brasileira de Zootecnia/Brazilian Journal of Animal Science, v. 36, p. 1462-1472, 2007.

FREAK, H. C.; GOVONI, K. E.; GUDA, K. HUANG, C.; ZINN, S. A Actions and interactions of thyroid hormone and zinc status in growing rats. Journal of Nutrition, v. 131, n. 4, p. 1135-1141, 2001.

GOLDENFARB, P. B.; BOWYER, F. P.; HALL, E.; BROSIUS, E. Reproducibility in the hematology laboratory: the microhematocrit determination. American Journal Clynic Patology, Baltimore, v. 56, n. 1 , p. 35-39. 1971.

GONÇALVES, G. S.; PEZZATO, L. E.; BARROS, M. M.; HISANO, H.; FREIRE, E. S.; FERRARI, J. E. C. Digestibilidade aparente e suplementação de fitase em alimentos vegetais para a tilápia-do-nilo. Acta Scientiarum, v. 26, n. 3, p. 313-321, 2004.

GONÇALVES, G. S.; PEZZATO, L. E.; BARROS, M. M.; KLEEMAN, G. K.; ROCHA, D. F. Efeitos da suplementação de fitase sobre a disponibilidade aparente de $\mathrm{Mg}, \mathrm{Ca}, \mathrm{Zn}, \mathrm{Cu}, \mathrm{Mn}$ e Fe em alimentos vegetais para a tilápia-do-nilo. Revista Brasileira de Zootecnia, v. 34, n. 6, p. 2155-2163, 2005.

GUIMARÃES, I. G.; PEZZATO, L. E.; BARROS, M. M.; TA- 
CHIBANA, L. Nutrient digestibility of cereal grain products and by-products in extruded diets for nile tilapia. Journal of the World Aquaculture Society. v. 39, n. 6, p. 781-789, 2008a.

GUIMARÃES, I. G.; PEZZATO, L. E.; BARROS, M. M. Amino acid availability and protein digestibility of several protein sources for Nile tilapia, Oreochromis niloticus. Aquaculture Nutrition, v. 14, p. 396-404, 2008 b.

HAMBIDGE, K. M.; CASEY, C. E.; KREBS, N. F. Zinc. In: MERTZ, W. (Ed.). Trace elements in human and animal nutrition. San Diego, EUA: Academic Press, 1986. p. 1-137.

HIDALGO, M. C.; EXPÓSITO, A.; PALMA, J. M.; HIGUERA, M. Oxidative stress generated by dietary $\mathrm{Zn}$-deficiency: studies in rainbow trout (Oncorhynchus mykis). International Journal of Biochemistry \& Cell Biology, v. 34, p. 183-193, 2002.

HISANO, H.; SOLARTE, W. N.; BARROS, M. M.; PEZZATO, L. E. Desempenho produtivo de alevinos de tilápia-do-nilo alimentados com levedura e derivados. Pesquisa Agropecuária Brasileira, v. 42, p. 1035-1042, 2007 a.

HISANO, H.; BARROS, M. M.; PEZZATO, L. E. Levedura desidratada de álcool e zinco como pró-nutrientes em rações para tilápia-do-nilo: aspectos hematológicos. Boletim do Instituto de Pesca, v. 33, p. 35-42, 2007 b.

JAIN, N. C. Schalm's veterinary hematology. 4. ed. Philadelphia: Lea \& Febeger, 1986.

JOHNSON, R. A.; WICHERN, D. W. Applied multivariate statistical methods. 3. ed. New Jersey, USA: Prentice-Hall, Englewood Cliffs, 1992.

KRAUS, A.; ROTH, H. P.; KIRCHGESSNER, M. Influence of vitamin $C$, vitamin $E$ and $\beta$-carotene on the osmotic fragility and the primary antioxidant system of erythrocytes in zinc-deficient rats. Archives for Tierernahrung, v. 50, p. 257-269, 1997.

LI, P.; GATLIN III, D. M. Evacuation of brewers yeast (Saccharomyces cerevisiae) as a feed supplement for hybrid striped bass (Morone chrysops X M. saxatilis). Aquaculture, v. 219, p. 681-692, 2003.

LI, P.; GATLIN III, D. M. Dietary brewers yeast and the prebiotic Grobiotic ${ }^{\mathrm{TM}} \mathrm{AE}$ influence growth performance, immune responses and resistance of hybrid striped bass (Morone chrysops $\times$ M. saxatilis) to Streptococcus iniae infection. Aquaculture, v. 231, p. 445-456, 2004.

NOGA, E. Fish leukocyte responses. In: FELDMAN, B. F.; ZINKL, J. G.; JAIN, N. C. Veterinary hematology. Hoboken: Wiley Blackwell. 5. ed. 2000, p. 436-439.

NATIONAL RESEARCH COUNCIL - NRC. Nutrient requeriments of fish. Washington, D. C.: National Academy of Science, 1993. $114 \mathrm{p}$.

Ci. Anim. Bras., Goiânia, v. 11, n. 3, p. 509-519, jul./set. 2010
O'DELL, B. L.; BROWNING, J. D.; REEVES, P. G. Zinc deficiency increases the osmotic fragility of rat erythrocytes. Journal of Nutrition, v. 117, p. 1883-1889, 1987.

ORTUÑO, J.; CUESTA, A.; RODRÍGUEZ, A.; ESTEBAN, M. A.; MESEGUER, J. Oral administration of yeast, Saccharomyces cerevisiae, enhances the cellular innate immune response of gilthead seabream (Spaurus aurata L.). Veterinary Immunology and Immunopathology, v. 85, p. 41-50, 2002.

PEZZATO, L. E.; MIRANDA, E. C.; BARROS, M. M. PINTO, L. G. Q.; FURUYA, W. M.; PEZZATO, A. C. Digestibilidade aparente de ingredientes pela tilápia-do-nilo (Oreochromis niloticus). Revista Brasileira de Zootecnia, v. 31, n. 4, p. 1595-1604, 2002.

PEZZATO, L. E.; MENEZES, A.; MARROS, M. M.; GUIMARÃES, I. G.; SCHICH, D. Levedura em dietas para alevinos de tilápia-do-nilo. Veterinária e Zootecnia, v. 13, n. 1, p. 84-94, 2006.

ROSSI, L.; MIGLIACCIO, S.; CORSI, A.; MARZIA, M.; BIANCO, P.; TETI, A.; CAMBELLI, L.; CIANFARANI, S.; PAOLETTI, F.; BRANCA, F. Reduced growth and skeletal changes in zincdeficient growing rats are due to impaired growth plate activity and inanition. Journal Nutrition, v. 131, p. 1142-1146, 2001.

RUMSEY, G. L.; WINFREE, R. A.; HUGHES, S. G. Nutritional values of dietary nucleic acids and purine bases to rainbow trout. Aquaculture, v. 108, p. 97-110, 1992.

SÁ, M. V. C.; PEZZATO, L. E.; BARROS, M. M.; PADILHA, P. M. Optimum zinc supplementation level in Nile tilapia Oreochromis niloticus juveniles diets. Aquaculture, v. 238, p. 385-401, 2004.

SÁ, M. V. C; PEZZATO, L. E.; BARROS, M. M.; PADILHA, P. M. Relative bioavailability of zinc in supplemental inorganic and organic sources for Nile tilapia Oreochromis niloticus fingerlings. Aquaculture Nutrition, v. 11, p. 273-281, 2005.

SÁNCHEZ-MUNIZ, F. J.; HIGUERE, M.; VARELA, G. Alterations of erythrocytes of the rainbow trout (Salmo gairdneri) by the use of Hansenula anomala yeast as sole protein source. Compendium Biochemistry Physiology, v. 72A, p. 693-696, 1982.

SANDSTRÖM, B. Nicronutrient interactions: effects on absorption and bioavailability. British Journal of Nutrition, v. 85, p. 181-185, sup. 2, 2001.

SCHOLZ-AHRENS, K. E.; SCHAAFSMA, C.; HEUVEL, E. G.; SCHREZENMEIR, J. Effects of probiotic on mineral metabolism. American Journal Clinical Nutrition, v. 73, p. 459S-464S, 2001.

SELVARAJ, V.; SAMPATH, K.; SEKAR, V. Administration of yeast glucan enhances survival and some non-specific and spe- 
cific immune parameters in carp (Cyprinus carpio) infected with Aeromonas hydrophila. Fish \& Sellfish Immunology, v. 19, p. 293-306, 2005.

TAVARES-DIAS, M.; MORAES, F. R. Hematologia de peixes teleósteos. Ribeirão Preto, SP: Willimpress Complexo Gráfico, 2004. 144 p.

TOVAR, D.; ZAMBONINO, J.; CAHU, C.; GATESOUPE, F. J.; VÁZQUEZ-JUÁREZ, R.; LÉSEL, R. Effect of live yeast incorporation in compound diet on digestive enzyme activity in sea bass (Dicentrarchus labrax) larvae. Aquaculture, v. 204, p. 113-123, 2002.
VRUWINK, K. J.; KEEN, C. L.; GERSHWIN, M. E.; MARESCHI, J. P.; HURLEY, L. S. The effect of experimental zinc deficiency on development of the immune system. In: CUNNINGHAM-RUNDLES, S. (Ed.). Nutrient modulation of the immune response. New Work: Marcel Dekker Inc, 1993. p. 263-279.

WATANABE, T.; KIRON, V.; SATOH, S. Trace minerals in fish nutrition. Aquaculture, v. 151, p. 185-207, 1997.

WINTROBE, M. M. Variations in the size and hemoglobin content of erythrocytes in the blood of various vertebrates. Folia Haema-

tologica, v. 51, p. 32-49. 1934.

Protocolado em: 22 abr. 2009. Aceito em: 11 maio 2010. 